\title{
Christopher Spehr
}

\section{Luther und das Konzil}

\section{Zur Entwicklung eines zentralen Themas in der Reformationszeit}



2010. XXI, 639 Seiten. BHTh 153

ISBN 978-3-16-151063-2

DOI 10.1628/978-3-16-151063-2

eBook PDF $144,00 €$

ISBN 978-3-16-150474-7

Leinen $144,00 €$
Das Konzil als kirchliche Institution und christliche Autoritätsinstanz avancierte während der Reformationszeit zu einem zentralen, religionspolitisch höchst strittigen Thema. Ausgelöst hatte die auf theologischen, kirchlichen und politischen Ebenen geführten Debatten Martin Luther, dessen Haltung zum Konzil bisher nicht eingehend untersucht worden ist. Christopher Spehr gelingt es, Luthers Einstellung sowohl zu den altkirchlichen und (spät-)mittelalterlichen Konzilien, als auch zu dem in den Reformationsjahrzehnten laut werdenden Konzilsbegehren einer differenzierten Analyse zu unterziehen. In welchen Konstellationen Luther sein Konzilsverständnis entwickelte und zeitlebens modifizierte, wird ebenso beantwortet, wie die Frage, mit welchen Intentionen Luther bisweilen ein »freies, christliches Konzil« einfordern konnte. Weil mit der Konzilsfrage zugleich auch die Problematik der kirchlichen Autoritätsinstanzen berührt wird, durchdringt diese Studie das gesamte, rechtfertigungstheologisch zentrierte Gefüge der Theologie Luthers.

Der Autor erhielt für das Werk den Hanns-Lilje-Preis 2010 der Akademie der Wissenschaften zu Göttingen.

Christopher Spehr Geboren 1971; Studium der Ev. Theologie in Bethel, Tübingen, Zürich; 2004 Promotion; 2009 Habilitation; seit 2011 Professor für Kirchengeschichte an der Theologischen Fakultät der Friedrich-Schiller-Universität Jena.

Jetzt bestellen:

https://mohrsiebeck.com/buch/luther-und-das-konzil-9783161510632?no_cache=1

order@mohrsiebeck.com

Telefon: +49 (0)7071-923-17

Telefax: $+49(0) 7071-51104$ 